OPEN ACCESS

Edited by: Claudio Cantù,

Linköping University, Sweden

Reviewed by:

Natalina Quarto,

Università degli Studi di Napoli

Federico II, Italy

Pierfrancesco Pagella,

University of Zurich, Switzerland

*Correspondence:

Guobin Yang

guobin.yang@whu.edu.cn

${ }^{\dagger}$ These authors have contributed equally to this work

Specialty section:

This article was submitted to Craniofacial Biology and Dental

Research,

a section of the journal

Frontiers in Physiology

Received: 07 June 2018

Accepted: 30 October 2018

Published: 20 November 2018

Citation:

Zhan Y, Li X, Gou X, Yuan G. Fan $M$ and Yang $G$ (2018) DLX3 Inhibits the Proliferation of Human Dental Pulp Cells Through Inactivation of Canonical Wnt/ $\beta$-Catenin Signaling Pathway. Front. Physiol. 9:1637. doi: 10.3389/fphys.2018.01637

\section{DLX3 Inhibits the Proliferation of Human Dental Pulp Cells Through Inactivation of Canonical Wnt/ $\beta$-Catenin Signaling Pathway}

\author{
Yunyan Zhan ${ }^{1+}$, Xiaoyan $\mathrm{Li}^{1,2+}$, Xiaohui Gou' ${ }^{1}$, Guohua Yuan, Mingwen Fan ${ }^{1}$ and \\ Guobin Yang ${ }^{1 *}$
}

1 The State Key Laboratory Breeding Base of Basic Science of Stomatology and Key Laboratory of Oral Biomedicine Ministry of Education, School and Hospital of Stomatology, Wuhan University, Wuhan, China, ${ }^{2}$ Shandong Provincial Key Laboratory of Oral Biomedicine, Department of Endodontics, School of Stomatology, Shandong University, Jinan, China

Homeodomain gene Distal-less-3 (D/x3) plays an important role during tooth development. Our previous studies indicate that DLX3 inhibits proliferation of human dental pulp cells (hDPCs). However, the mechanism of DLX3 regulating proliferation of hDPCs and maintaining the quiescence of the cells remain unknown. Given the importance of canonical Wnt signaling in the proliferation of dental pulp cell and tooth development, we hypothesized that DLX3 inhibited proliferation of hDPCs through inactivation of canonical Wnt signaling. With overexpression or knock-down of DLX3 in primary hDPCs, we found DLX3 down regulated canonical Wnt signaling and its downstream target genes. And when the DLX3 overexpressed-cells were treated with lithium chloride, the proliferation inhibition by DLX3 was reversed. We also found that DLX3 enhanced the expression of DKK1 and the reduced proliferation of hDPCs by DLX3 was reversed with knock-down of DKK1. Furthermore, luciferase reporter assay and chromatin immunoprecipitation assay showed DLX3 was able to bind to Dkk1 promoter region from nucleotides (nt) -1656 to -1245 , and stimulated Dkk1 promoter activity. Mutagenesis studies further revealed two DLX3 responsive elements in Dkk1 promoter. Taken together, our data indicate that DLX3 inhibits proliferation of hDPCs via inactivation of $\mathrm{Wnt} / \beta$-catenin signaling pathway by directly binding to $D k k 1$ promoter and increasing its expression.

Keywords: DKK1, DLX3, human dental pulp cells, proliferation, Wnt/ß-catenin signaling

\section{INTRODUCTION}

Dental pulp is mainly derived from neural crest cells and contains a mixed population of odontoblasts, fibroblasts, and undifferentiated stem/progenitor cells (Sinanan et al., 2004; Li et al., 2012). The main functions of dental pulp are dentinogenesis and maintaining the vitality of the dentin biologically and physiologically (Tatullo et al., 2015). Dentinogenesis is a progress involving the differentiation of preexisting undifferentiated stem/progenitor cells into odontoblasts and the formation of dentin. With mild or moderate dentin trauma, the secretion of dentin matrix by odontoblasts is increased and results in the formation of reactionary 
dentin that protects the pulp against damage. While with deep dentin lesions or injuries, original odontoblasts initially undergo cell death, and quiescent pulp stem/progenitor cells re-enter the cell cycle, proliferate and subsequently migrate to the pulp-dentin border behind injury region. Then these cells differentiate into a new generation of odontoblast-like cells, which secrete reparative dentin around the injury site and repair the dentin tissue (Harichane et al., 2011; Yan et al., 2011; Potdar and Jethmalani, 2015; Lv et al., 2016). However, under normal physiological conditions, as the only vascularized dental tissue that is encapsulated in rigid mineralized dentin structures, the dental pulp cells (DPCs) usually exhibit inhibited proliferation capacity (at quiescent state) (Yan et al., 2011), which makes homeostasis of the dental pulp (Gong et al., 2012). Many investigations were focused on the increased proliferation capacity of DPCs in response to decays or injuries, but the mechanism to maintain the very important inhibited proliferation ability of DPCs under normal condition is dismissed.

Distal-less3 (DLX3), as a transcription factor, is essential during embryo development (Morasso et al., 1999) and plays crucial roles in placental formation, epidermis development, and ectodermal appendages development (Morasso et al., 1995; Isaac et al., 2014). During early development, $D l \times 3$ is expressed in neural crest cells in branchial arches by E9.5 (Robinson and Mahon, 1994), and is firstly detected in dental epithelium and later extends to all dental area including epithelium and mesenchyme during the tooth morphogenesis (Zhao et al., 2000). In human, mutation of DLX3 is responsible for tricho-dentoosseous (TDO) syndrome, which is a rare autosomal dominant disorder and characterized by defects in hair, teeth, and other ectodermal appendages (Zhao et al., 2000; Hwang et al., 2008). In mice, deletion of $D l x 3$ in neural crest severely impairs the odontoblast differentiation, dentin production, and transcription of Dspp (Duverger et al., 2012). Our previous study showed that DLX3 inhibited the proliferation of human DPCs (hDPCs) (Li et al., 2012). However, the molecular mechanism of DLX3 inhibiting hDPCs proliferation has not been elucidated.

Wnt signaling plays important role in regulating cell proliferation, differentiation, and polarity (Logan and Nusse, 2004; Rattanawarawipa et al., 2016). The canonical Wnt pathway mediates signaling through regulating intracellular level and subcellular localization of $\beta$-catenin. Without Wnt ligand, the enzyme glycogen synthase kinase $3 \beta$ (GSK3 $\beta$ ) will phosphorylate the cytoplasmic $\beta$-catenin, then the phosphorylated $\beta$-catenin will be further ubiquitylated and degraded (Rao and Kuhl, 2010). When Wnt ligand binds to its receptors, $\beta$-catenin will not be phosphorylated and the stabilized high level cytoplasmic $\beta$-catenin will be translocated into the nucleus. Then, a transcriptional complex will be formed by $\beta$-catenin and T-cell factor (Tcf)/lymphoid enhancer-binding factor (Lef) in the nucleus (MacDonald et al., 2009; Kim J.H. et al., 2013), which then activates expression of Wnt downstream genes such as CyclinD1, C-myc, and so on (Bejsovec, 2005; Liang et al., 2017). Inhibitory protein such as Dickkopf related protein 1 (DKK1) can inhibit Wnt signaling by preventing the binding of Wnt ligand with its receptor (Cruciat and Niehrs, 2013; Zhou et al., 2016).
Wnt/ $\beta$-catenin signaling pathway plays important roles in different developmental stages of ectodermal appendages including teeth (Liu et al., 2008; Ahn et al., 2010). During tooth development, the expression of Lef1 and Fgf3 and the formation of primary enamel knot depend on the mesenchymal $\beta$-catenin (Chen et al., 2009; Du et al., 2012). Moreover, the Wnt/ $\beta$-catenin signaling pathway has important functions on mineral matrix deposition (Aurrekoetxea et al., 2016) and odontogenic differentiation (Kim T.H. et al., 2013; VialeBouroncle et al., 2015). In mice, tooth development is arrested at bud stage due to the depletion of dental mesenchymal $\beta$-catenin (Sasaki et al., 2005). In human, mutation of Wnt10a, a canonical Wnt family member, has been shown to cause odonto-onychodermal dysplasia, an autosomal recessive ectodermal dysplasia characterized by defective tooth development (Adaimy et al., 2007). Previous study showed that WNT10A promoted the proliferation of hDPCs (Zhang et al., 2014). Thus, we proposed that DLX3 might inhibit proliferation and maintain the quiescent state of hDPCs by inhibiting Wnt signaling pathway.

In our study, we investigated the molecular mechanism of DLX3 in regulating hDPCs proliferation and found that DLX3 inhibited the proliferation of hDPCs through inactivation of Wnt signaling pathway via increasing DKK1 expression.

\section{MATERIALS AND METHODS}

\section{Isolation and Culture of hDPCs}

Dental pulp tissues were obtained from extracted healthy human premolars for orthodontic treatment (12-14 years old) with informed consents. All the procedures were approved by the Ethics Committee of the School of Stomatology, Wuhan University. After extraction, the tooth was washed three times with phosphate-buffered saline solution (PBS, Invitrogen, Carlsbad, CA, United States). The pulp tissue was gently separated from the teeth and cut into small pieces (approximately $1 \mathrm{~mm}^{3}$ in size). The tissue pieces were seeded into a T25 cell culture bottle in Dulbecco's Modified Eagle Medium (DMEM, Gibco-BRL, Grand Island, NY, United States) supplemented with $10 \%$ fetal bovine serum (FBS, Gibco-BRL) and antibiotics. Upon reaching confluence, cells were passaged at a threefold dilution. The cells between passage 2 and 6 were used in this study. For lithium chloride $(\mathrm{LiCl})$ treatment, hDPCs were pre-treated with $20 \mathrm{mM}$ LiCl (Sigma, St. Louis, MO, United States) for $24 \mathrm{~h}$ before collecting.

\section{Lentiviral Infection}

To continuously overexpress DLX3, hDPCS were infected with lentivirus using pLL3.7-Dlx3 plasmid and packaging plasmids as described previously (Li et al., 2012). Cells successfully infected with Dlx3 lentiviral particles were assigned as hDPC/Dlx3. Control cells infected with empty vector and wild-type hDPCs were assigned as hDPC/pLL3.7 and hDPC/wt, respectively.

\section{Western Blot}

Cells were harvested and lysed for total protein in RIPA lysis buffer (Thermo Scientific, EU, Lithuania) with protease 
inhibitors. Proteins were separated by sodium dodecyl sulfate polyacrylamide gel (SDS-PAGE) and subsequently transferred to polyvinylidene fluoride (PVDF) membrane. Membranes were then incubated with anti-DLX3, anti-CyclinD1, anti-Cmyc, anti-Tcf-7, anti-DKK1, anti- $\beta$-actin, anti-GAPDH (all from Abcam, Cambridge, MA, United States), and anti-active$\beta$-catenin antibodies (Millipore, Burlington, MA, United States) overnight at $4^{\circ} \mathrm{C}$. Horseradish peroxidase (HRP)-conjugated secondary antibodies (1:10,000) and chemiluminescence substrate were used to detect the immunoreactive bands with autoradiography film. Protein levels were quantitatively analyzed with Image $J$ (National Institutes of Health, Bethesda, MD, United States) with $\beta$-actin as the loading control.

\section{Quantitative Real-Time PCR (qPCR)}

Total RNAs were isolated with EZNA Total RNA Kit I (Omega, Norcross, GA, United States) and were reverse transcribed by using Revert Aid First Strand cDNA Synthesis Kit with gDNA Eraser (Thermo Scientific). qPCR was conducted with the ABI Prism 7500 Real-Time PCR System (Life Technologies, Foster City, CA, United States) with SYBR green master mix (Roche Diagnostics, Indianapolis, IN, United States). Specificity of qPCR in each sample was confirmed by melting curve analyses. The relative mRNA expression was normalized to the control glyceraldehyde-3-phosphate dehydrogenase (Gapdh). The primers designed for Dlx3, Dkk1, CyclinD1, C-myc, and Gapdh are listed in Table 1.

\section{Immunofluorescence Staining}

Cells seeded on coverslips were cultured for $24 \mathrm{~h}$ after attachment. After washing with cold PBS, cells were fixed with $4 \%$ paraformaldehyde for $15 \mathrm{~min}$ at room temperature, permeabilized with $0.25 \%$ Triton $\mathrm{X}$, and blocked in $3 \%$ BSA at $37^{\circ} \mathrm{C}$ for $1 \mathrm{~h}$. Cells were finally incubated with antiactive- $\beta$-catenin or anti-DKK1 primary antibody at $4^{\circ} \mathrm{C}$ overnight. Then cells were incubated with Alexa Fluor 488or 594-conjugated secondary antibody (Abcam), followed by counterstaining with 4',6-diamidino-2-phenylindole (DAPI).

\section{EdU Staining}

The proliferation ability of cells was assessed by EdU Staining with the Cell-Light EdU DNA cell proliferation kit (RiboBio, Guangzhou, China). Briefly, hDPCs cultured in 24-well plate were incubated with $30 \mu \mathrm{M}$ 5-ethynyl-2'-deoxyuridine (EdU) for $3 \mathrm{~h}$. Nuclei were stained with DAPI. The EdU-positive cells and total cells were calculated and the ratio of EdU-positive cells to total cells was statistically analyzed between groups.

\section{RNA Interference}

To knock-down the endogenous DLX3 or DKK1 expression, small interference RNA (siRNA) targeted human Dlx3 (Dlx3 siRNA, GenePharma, Suzhou, China) or human Dkk1 (Dkk1 siRNA, Sigma) or negative control siRNA (Neg. siRNA, Sigma) were transfected into cells at a final concentration of $40 \mathrm{nM}$
TABLE 1 | Primer sequences used for qPCR amplification.

\begin{tabular}{|c|c|c|}
\hline Gene & Sequence $\left(5^{\prime}-3^{\prime}\right)$ & Size (bp) \\
\hline \multirow[t]{2}{*}{$D / x 3$} & Forward: CCTATGGCCAGACGGTGAAC & 222 \\
\hline & Reverse: GCACTCCTCGTCCTCTG & \\
\hline \multirow[t]{2}{*}{ Dkk1 } & Forward: CTCGGTTCTCAATTCCAACG & 120 \\
\hline & Reverse: TTTCTGTTGCCACTGCTGGGAC & \\
\hline \multirow[t]{2}{*}{ C-myc } & Forward: CCACACATCAG ACAACTACGCT & 100 \\
\hline & Reverse: GCATITCGGTTGTTGCTGATC & \\
\hline \multirow[t]{2}{*}{ CyclinD1 } & Forward: AGGTCTGCGAGGAACAGAAGTG & 137 \\
\hline & Reverse: TGCAGGCGGCTCTIITC & \\
\hline \multirow[t]{2}{*}{ Gapdh } & Forward: TCATGGGTGTGAACCATGAGAA & 146 \\
\hline & Reverse: GGCATGGACTGTGGTCATGAG & \\
\hline
\end{tabular}

with Lipofectamine 2000 (Invitrogen). Forty-eight hours after transfection, the cells were subjected to Western blot or qPCR or EdU staining. Cells transfected with $D l \times 3$ siRNA were assigned as $\mathrm{hDPC} / \mathrm{Dlx} 3$ si.

\section{Construction of Reporter Plasmids and Mutagenesis}

The human $D k k 1$ promoter region from -1656 to +398 relative to the position of the transcription start site $(+1)$ was amplified by PCR using human genomic DNA as template with the following primer pairs ( $p 1656)$ : forward: $5^{\prime}$-cgcctcgagCTAC TCG AGCTATAGTAGGTCAGCATGTGGAGTC-3'; reverse: 5'-cgcaa gcttACGAAGCTT AGGTCAGAGCATCCTCTG AGT- $3^{\prime}$. Other fragments with different lengths in the $5^{\prime}$-flanking region were amplified by $\mathrm{PCR}$ using p1656 as template with the same reverse primer and the following forward primers: p1245, 5'-cgcctcgagCTACTCGAG GGCTCTAGGCTTCCAAT AAGT-3'; p845, 5' -cgcctcgagCTACTCGAGCTGCCTA ATCAA GTTCATCTACCG- $3^{\prime}$. All the PCR forward primers and reverse primers contain a $5^{\prime}$-cgcctcgag-XhoI overhang and a $5^{\prime}$-cgc aagctt-HindIII overhang, respectively. All the PCR products were gel-purified and finally subcloned into the pGL3-Basic vector (Promega, Madison, WI, United States) after digesting with HindIII and XhoI (New England Biolabs, Ipswich, MA, United States). To construct the mutant reporter plasmids ( $l \times 3 I$ Del, Dlx3II Del, Dlx3III Del, and Dlx3IV Del), QuikChange II Site Directed Mutagenesis Kit (Agilent Technologies, Santa Clara, CA, United States) was used with p1656 as template and following oligonucleotide primers: Dlx3I Del, forward 5'-TAAATAT ATC TTATCTTTTTCAATAGTGATTATTCAATCAC-3', reverse 5'-GTGATTGAA TAATCACTAT TGAAAAAAGTAAGATAT ATTTA-3', Dlx3II Del, forward 5' -AT ATCAACCTGTTTTTAA AAGTG TATGCTT-3', reverse 5' -CAATAAATATAAAA GCA TACACTTTTAAAAACAGGTTGATAT-3', Dlx3III Del, forward 5'-ATGCT TTTATATTTATTGCTATTATTGTTACTAC ATCTTTTA-3', reverse 5'-TAAAAG ATGTAGTAACAATAA TAGCAATAAATATAAAAGCAT-3', and Dlx3IV Del, forward $5^{\prime}$-CTACATCTTTTATTATTACTGGAATAAAGAGAACTTTAT TAT-3' ${ }^{\prime}$, reverse 5' -ATAATAAAGTTCTCTTTATTCCAGTAATA ATAAAAGATGTAG-3'. All mutant constructs were verified by DNA sequencing. 


\section{Dual Luciferase Reporter Assay}

293T cells grown in 48-well plates were transfected with pGL3-Basic vector or the reporter plasmids, or mutant reporter plasmids and pRL-TK Renilla luciferase expression vector (Promega) as an internal control as well as human DLX3 overexpressing plasmid (pcDNA3.1-Dlx3). After $48 \mathrm{~h}$, the cells were collected and lysed. Luciferase activities were measured according to the Dual Luciferase reporter assay system (Promega). Relative luciferase activities were determined by normalizing each Firefly luciferase activities to Renilla luciferase activities. All experiments were conducted at least three times.

\section{Chromatin Immunoprecipitation (ChIP)}

293T cells were co-transfected with p1656 with or without pcDNA3.1-Dlx3 for $48 \mathrm{~h}$. Chromatin immunoprecipitation (ChIP) assay was conducted with the ChIP assay kit (Upstate Technology, Richfield Springs, NY, United States) as described previously (Yang et al., 2017). AntiDLX3 antibody or negative control IgG was used for immunoprecipitation. The purified immunoprecipitated DNA was analyzed by PCR to amplify promoter regions of the $D k k 1$ gene using the following primers: forward ${ }^{-1656} 5^{\prime}$ CTATACAGCTTAGAGGAAGACAAAATA- $3^{\prime-1230}$, reverse $-12715^{\prime}$-CAAAT ATTTATGAGACACAGCTCTCAT- $3^{\prime-1245}$. The input DNA from samples before immunoprecipitation was used for the positive control.

\section{Statistical Analysis}

Each experiment was conducted at least three times. The data were presented as means \pm standard deviation. Statistical analyses were conducted by one-way analysis of variance by using the GraphPad Prism, PC version 7 (GraphPad software). $P<0.05$ was considered statistically significant.

\section{RESULTS}

\section{DLX3 Inactivates Canonical Wnt/ $\beta$-Catenin Pathway in hDPCs}

To evaluate whether DLX3 inactivates Wnt/ $\beta$-catenin signaling pathway in hDPCs, active $\beta$-catenin, an indicator of canonical Wnt signaling activity, was detected by Western blot. As shown in Figure 1A, the expression of active $\beta$-catenin was decreased in $\mathrm{hDPC} / D l x 3$ cells. CyclinD1, C-myc and Tcf-7 were known as target genes of canonical Wnt/ $\beta$-catenin signaling pathway (Arya et al., 2015; Kaur et al., 2015). As expected, the expressions of CyclinD1, C-myc, and Tcf-7 were also decreased in hDPC/Dlx3 cells (Figure 1A). Then, the endogenous DLX3 in hDPCs were knocked down with Dlx3 siRNA, and the expression of active $\beta$-catenin was increased (Figure 1B). qPCR showed the similar results to that of Western blot (Figure 1C). To further confirm the inhibition of canonical Wnt $/ \beta$-catenin by DLX3, the subcellular localization of active $\beta$-catenin in hDPCs were detected by immunofluorescence staining. In $\mathrm{hDPC} / w t$ and hDPC/pLL3.7 cells, active $\beta$-catenin was highly expressed in both cytoplasm and nucleus (Figure 1D). However, in hDPC/Dlx3 cells active $\beta$-catenin was only expressed in cytoplasm but not in nuclei (Figure 1D). All these results indicated that DLX3 inactivated the canonical $\mathrm{Wnt} / \beta$-catenin signaling in hDPCs.

\section{DLX3 Inhibits Proliferation of hDPCs Through Inactivation of Wnt Signaling}

$\mathrm{LiCl}$ is able to activate canonical Wnt/ $\beta$-catenin signaling by inhibiting GSK-3 $\beta$ (Hedgepeth et al., 1997). To further test whether DLX3 inhibits proliferation of hDPCs via inactivation of Wnt signaling, cells were treated with $20 \mathrm{mM} \mathrm{LiCl}$. Then the cell proliferation was measured with EdU labeling assay. The cell proliferative rate in $\mathrm{hDPC} / D l \times 3$ cells was dramatically suppressed compared with that in $\mathrm{hDPC} / w t$ and $\mathrm{hDPC} / \mathrm{pLL} 3.7$ cells, but was significantly reversed when cells were treated with $\mathrm{LiCl}$ (Figures 2A,B), which suggested that DLX3 inhibited the proliferation of hDPCs through inactivation of Wnt signaling pathway. In addition, Western blot confirmed the activation of canonical Wnt/ $\beta$-catenin signaling with $\mathrm{LiCl}$ treatment by detecting the expression of active $\beta$-catenin (Figure 2C).

\section{DLX3 Inhibits Proliferation of hDPCs via Increasing DKK1 Expression}

Immunofluorescence staining showed that the expression of DKK1, an antagonist of Wnt signaling pathway, was increased in $\mathrm{hDPC} / D l \times 3$ cells, and decreased in $\mathrm{hDPC} / D l \times 3$ si cells, compared with that in $\mathrm{hDPC} / w t$ cells (Figure 3A). Western blot and $\mathrm{qPCR}$ results also showed that overexpression of DLX3 enhanced DKK1 expression in hDPCs (Figures 3B,C). To further investigate whether DLX3 inhibits proliferation of hDPCs via increasing DKK1 expression, Dkk1 siRNA was transfected into hDPC/Dlx3 cells or hDPC/wt cells. The knock-down efficiency of $D k k 1$ siRNA was confirmed by qPCR, which showed the expression of endogenous $D k k 1$ was reduced more than $70 \%$ when cells transfected with Dkk1 siRNA compared with cells transfected with control siRNA (Figure 3D). EdU staining showed that the reduced proliferation of hDPCs by DLX3 overexpression was reversed with knock-down of DKK1 (Figure 3E). All these results indicated that DLX3 inhibited the proliferation of hDPCs through downregulation of Wnt/ $\beta$-catenin signaling pathway via increasing DKK1 expression.

\section{DLX3 Increases DKK1 Expression by Directly Stimulating Dkk1 Promoter Activity}

To assess whether induction of DKK1 expression is through directly stimulating $D k k 1$ promoter activity, luciferase reporters containing different lengths of $D k k 1$ promoters, $p 845, p 1245$, and p1656, were constructed (Figure 4A) and transfected into 293T cells. Luciferase activity was measured with co-transfection of pcDNA3.1-Dlx3 vector (Figure 4B). Overexpression of DLX3 failed to increase transcription activates of $p 845$ and p1245 compared with transfection of pGL3-Basic, but significantly increased the transcription activity of $p 1656$, which suggested DLX3 was able to stimulate Dkk1 promoter activity from nucleotides (nt) -1656 to -1245 . To further confirm the direct 

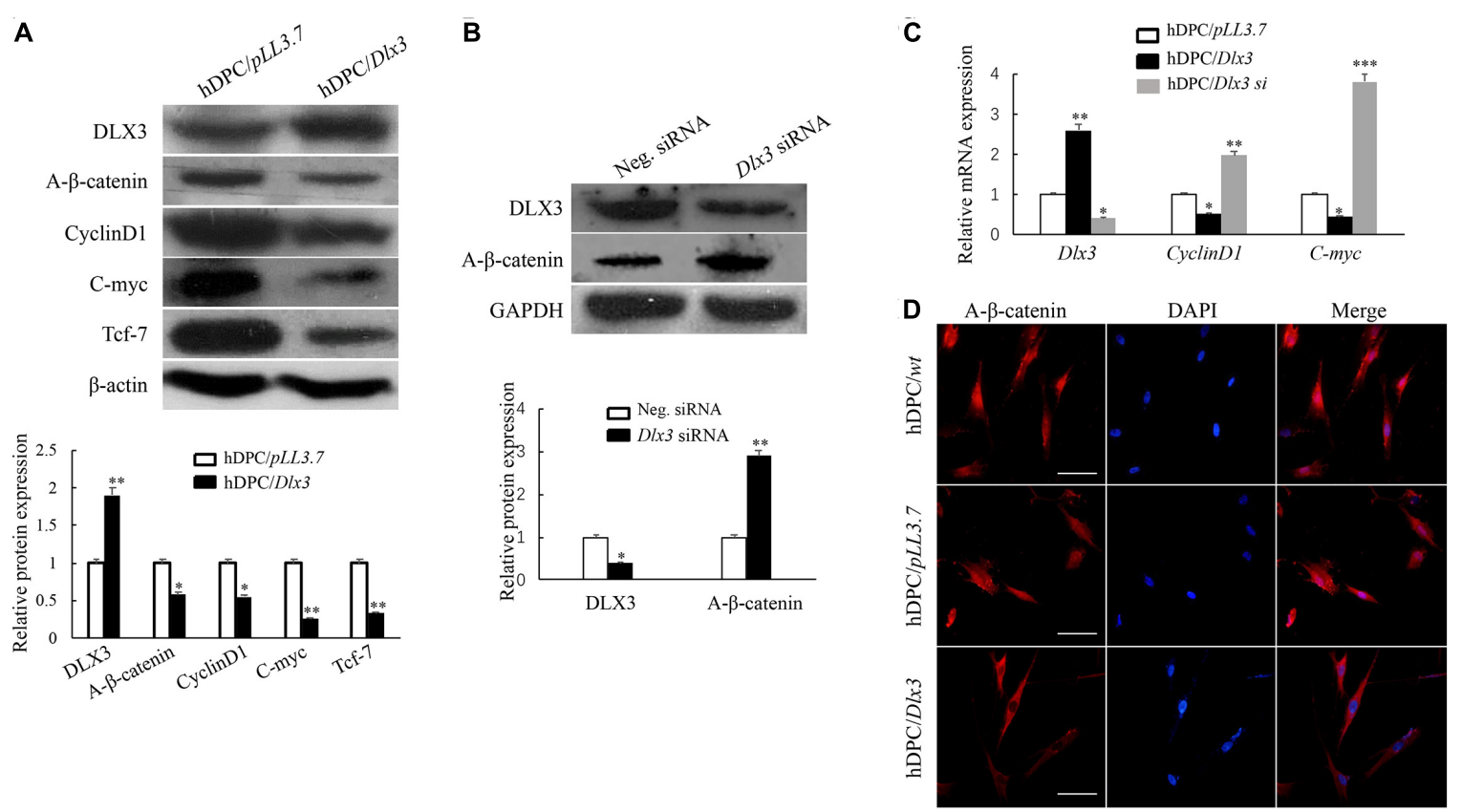

FIGURE 1 | DLX3 inactivates canonical Wnt/ $\beta$-catenin pathway in hDPCs. (A) Western blot showed the expressions of DLX3, active $\beta$-catenin (A- $\beta$-catenin), CyclinD1, C-myc, Tcf-7 and $\beta$-actin in hDPC/pLL3.7 and hDPC/D/x3 cells. Lower part shows the quantitative analysis. (B) Western blot showed the expression of DLX3 and active $\beta$-catenin in hDPCs transfected with negative control siRNA or D/X3 siRNA. Lower part shows the quantitative analysis. (C) qPCR showed the relative mRNA expressions of $D / \times 3$, CyclinD1 and $C$-myc in hDPC/pLL3.7, hDPC/D/x3 and hDPC/D/x3 si cells. ${ }^{*} P<0.05,{ }^{* *} P<0.01,{ }^{* * *} P<0.001$.

(D) Immunofluorescence staining showed the subcellular localization of active $\beta$-catenin in hDPC/wt, hDPC/pLL3.7 and hDPC/D/x3 cells. Scale bars $=50 \mu \mathrm{m}$.

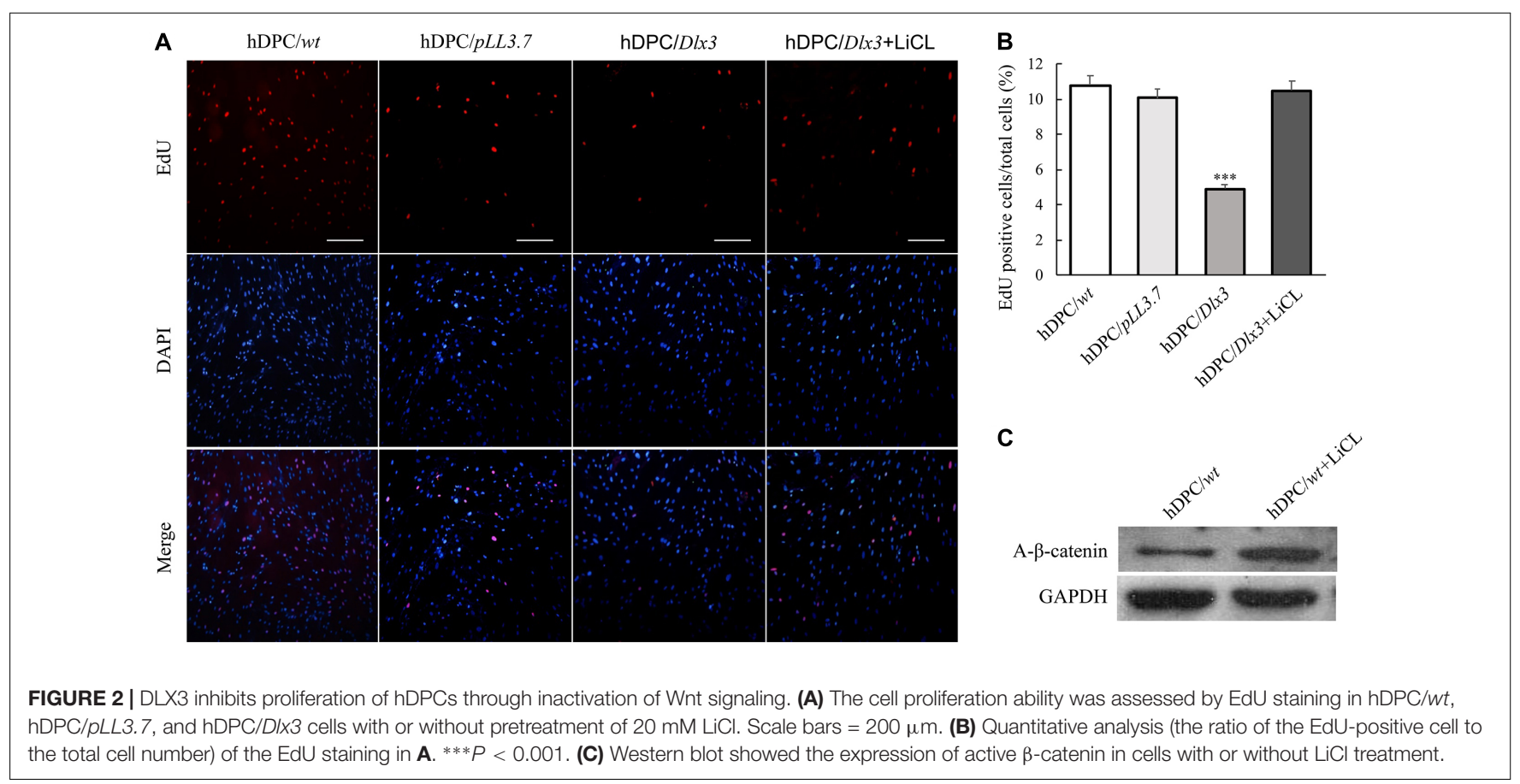

binding of DLX3 with nt -1656 to -1245 of $D k k 1$ promoter in vivo, ChIP assay was performed. PCR was conducted with the immunoprecipitated and purified DNA as template and the oligonucleotides corresponding to the 5-flanking region (from nt -1656 to -1245 ) of $D k k 1$ promoter as primers. As expected, PCR band was detected (Figure 4C, Lane 2, upper band) and was more intense when the cells were co-transfected with pcDNA3.1-Dlx3 plasmid (Figure 4C, Lane 1, upper band). 


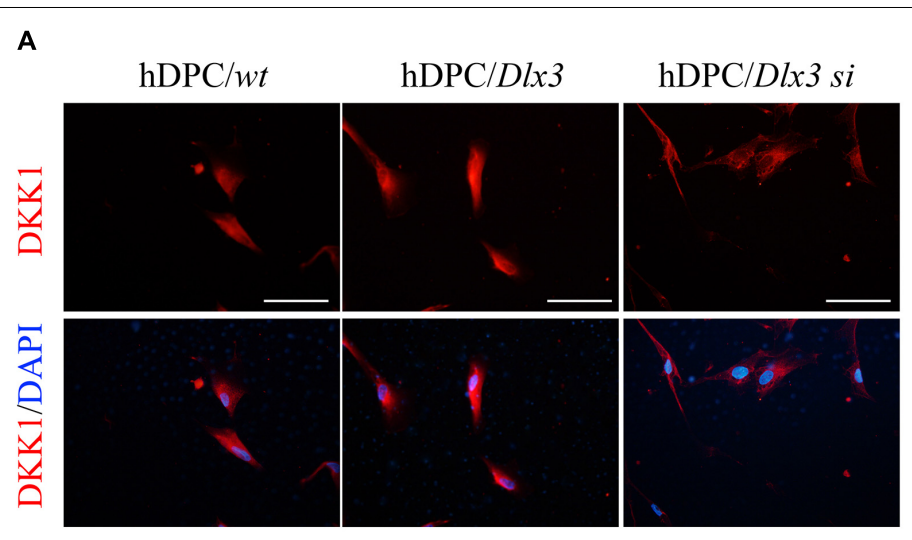

B
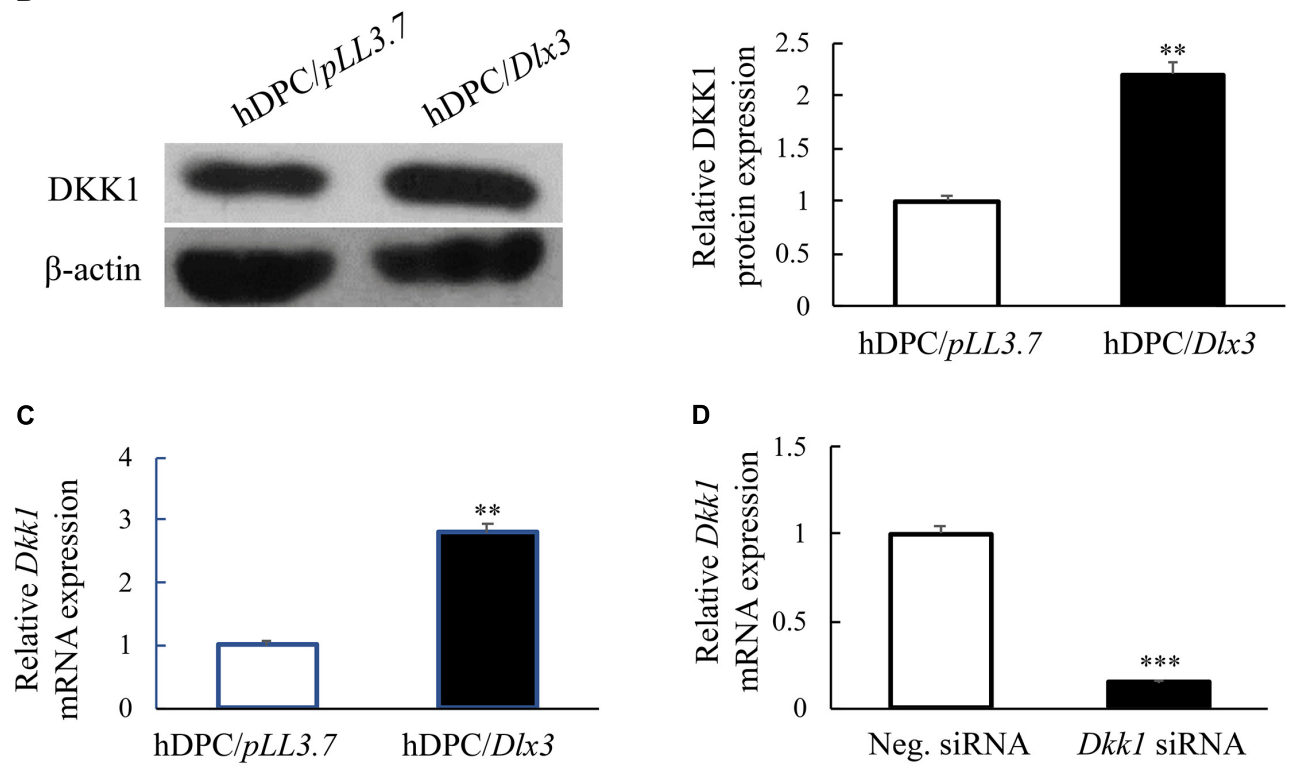

E

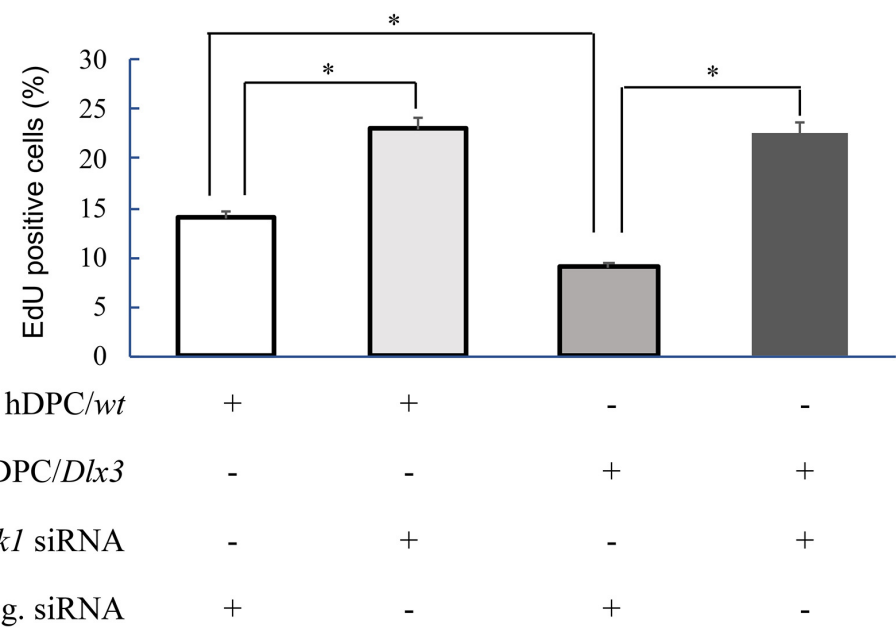

FIGURE 3 | DLX3 inhibits proliferation of hDPCs via increasing DKK1 expression. (A) The expressions of DKK1 in hDPC/wt, hDPC/D/X3, and hDPC/D/X3 si cells were detected by immunofluorescence staining. Scale bars $=50 \mu \mathrm{m}$. (B,C) Western blot and qPCR showed the protein and mRNA expression of DKK1 in hDPC/pLL3.7 and hDPC/D/x3 cells. (D) qPCR showed the relative Dkk1 mRNA expression in hDPCs transfected with negative control siRNA or Dkk1 siRNA. (E) Cell proliferation ability was assessed by EdU staining in hDPC/wt or hDPC/pLL3.7 cells with transfection of negative control siRNA or Dkk1 siRNA. ${ }^{*} P<0.05$, ${ }^{* *} P<0.01,{ }^{* * *} P<0.001$. 


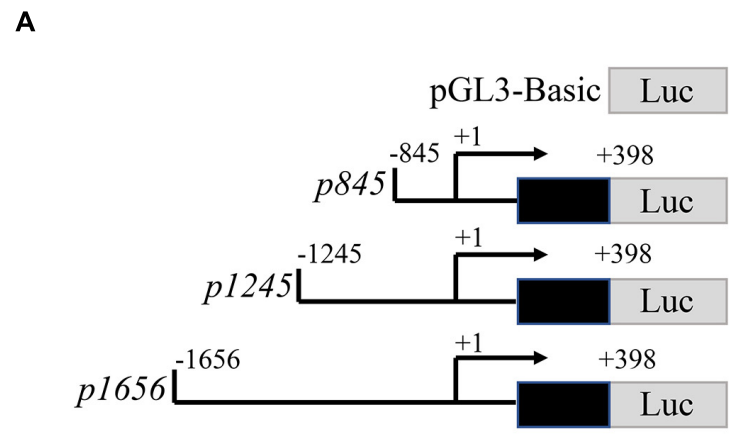

C

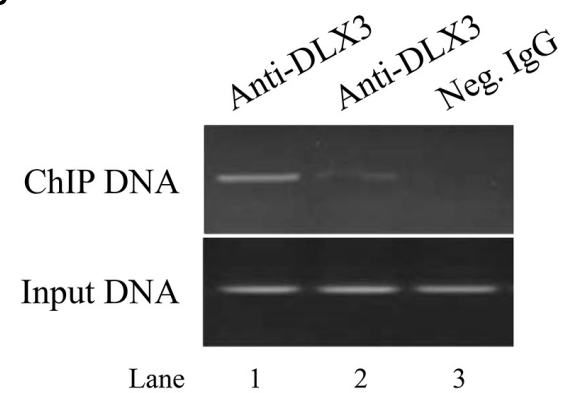

B

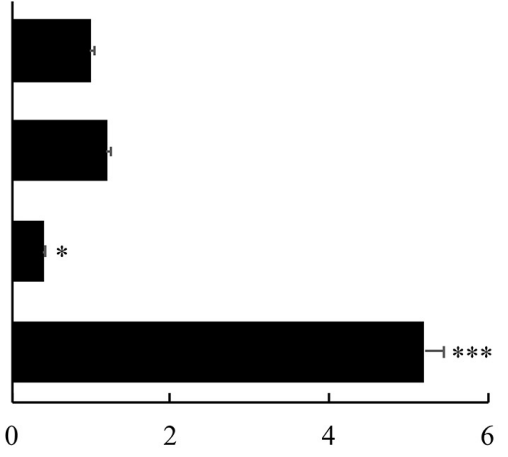

Fold Activation

E
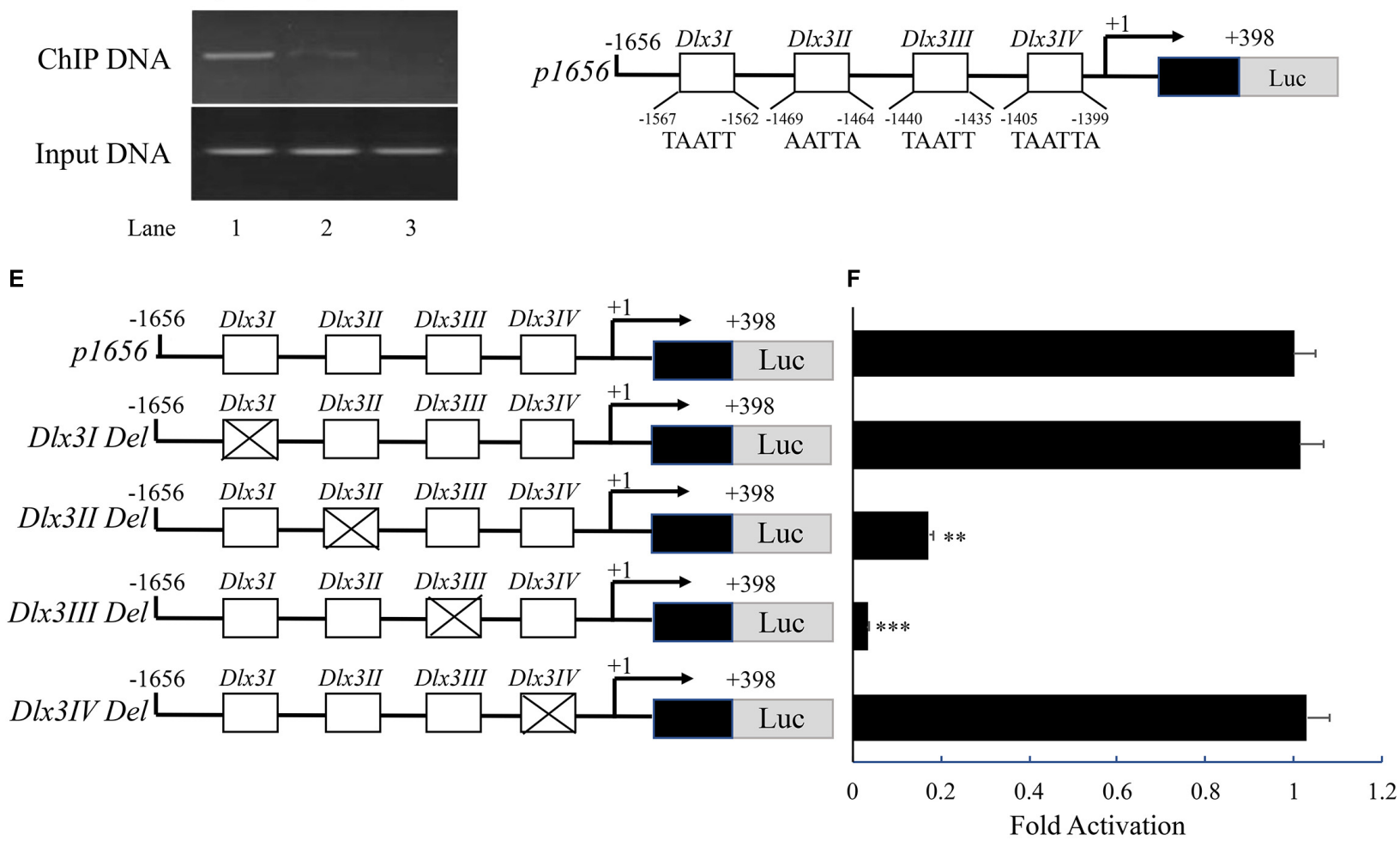

FIGURE 4 | DLX3 increases DKK1 expression by directly stimulating Dkk1 promoter activity. (A) Schematic representation of reporter constructs with different lengths of Dkk1 promoter. (B) 293T cells were co-transfected with pGL3-Basic or p845 or p1245 or p1656 as well as pcDNA3.1-Dlx3 plasmids. Luciferase activity was determined. ${ }^{*} P<0.05,{ }^{* * *} P<0.001$, compared with pGL3-Basic group. (C) ChIP assay demonstrated the binding of DLX3 with Dkk1 promoter. Neg. IgG, Negative control IgG. (D) Illustration of core sequence of four DLX3 responsive elements: D/×3I, D/x3/I, D/x3/I, and D/×3/V. (E) Schematic representation of wild type and mutant p1656 reporter constructs. (F) 293T cells were co-transfected with wild type or mutant p1656 reporter constructs as well as pcDNA3.1-Dl×3 plasmid. Luciferase activity was determined. ${ }^{* *} P<0.01,{ }^{* * *} P<0.001$, compared with wide type $p 1656$ group.

Positive control was set using input DNA as template (Figure 4C, lower bands), and negative control was set using negative control IgG (Figure 4C, Lane 3). These results indicated that DLX3 is able to directly bind to $D k k 1$ promoter region from nt -1656 to -1245 , and stimulates $D k k 1$ promoter activity.

It is known DLX3 binds to a conserved sequence of TAATT (Feledy et al., 1999). Analysis of the promoter region from nt -1656 to -1245 of $D k k 1$ gene revealed four potential DLX3 responsive elements (Dlx3I, Dlx3II, Dlx3III, and Dlx3IV; Figure 4D). To further confirm whether DLX3-induced Dkk1 promoter activity is mediated by these potential responsive elements, four $p 1656$ mutant constructs with deletion of DLX3 responsive elements were generated (Figure 4E). p1656 or p1656 mutant reporter constructs with pcDNA3.1-Dlx3 plasmid were 
co-transfected into 293T cells. Luciferase reporter assay showed that deletion of either Dlx $3 I$ or $D l x 3 I V$ did not change the response activity of $p 1656$ to DLX3, but deletion of either Dlx3II or Dlx3III did significantly suppress the response activity of p1656 to DLX3 (Figure 4F), which indicated that DLX3-induced $D k k 1$ promoter activity is mediated by Dlx3II and Dlx3III elements.

\section{DISCUSSION}

Our present investigation revealed the underlying mechanism of DLX3 controlling the proliferation and maintaining quiescence of hDPCs. DLX3 is able to enhance DKK1 expression in $\mathrm{hDPCs}$, then suppresses Wnt/ $\beta$-catenin signaling and inhibits the proliferation of hDPCs.

DKK1 is a typical antagonist of $\mathrm{Wnt} / \beta$-catenin signaling by competing for the Wnt receptor lipoprotein receptor related protein (LRP)5/6 (Kawano and Kypta, 2003). During mouse molar morphogenesis, $D k k 1$ is primarily expressed in dental mesenchyme, including preodontoblasts (Fjeld et al., 2005). Postnatally, $D k k 1$ is prominently expressed in the preodonto- and odonto-blasts (Fjeld et al., 2005). In Dkk1 transgenic mice, with overexpression of Dkk1 in dental pulp and odontoblasts, the molar shows an increase of immature odontoblasts, few mature odontoblasts and dramatic change in Osx and nestin expression (Han et al., 2011). The present investigation found the enhanced DKK1 in hDPC/Dlx3 cells suppressed Wnt/ $\beta$-catenin signaling and inhibited the proliferation of hDPCs. These results are consistent with previous studies, which showed that the DKK1 inhibited the proliferation of several types of cells, including human retinal pigment epithelial cells, periosteal cells, osteosarcoma cells, via downregulation of $\mathrm{Wnt} / \beta$-catenin signaling pathway (Kim H.K. et al., 2013; Liu et al., 2014; Zhou et al., 2016).

We identified Dkk1 as a target gene of DLX3, which is supported by the increased expression level of DKK1 in $\mathrm{hDPC} / D l \times 3$ cells. To further elucidate the mechanism of upregulation of the DKK1 expression by DLX3, a series of tests focused on Dkk1 promoter was performed. Luciferase reporter assay showed the transcription activity of $p 1656$ was significantly enhanced compared with that of $p 1245, p 845$, and pGL3-Basic vector with transfection of DLX3 expression vector, which indicated DLX3 can activate $D k k 1$ promoter from nt -1656 to -1245 . Then we found either endogenous or overexpressed DLX3 can bind with this promoter region using ChIP assay, and four potential DLX3 response elements were found in this region. Furthermore, with mutation of each binding elements, we found only two DLX3 response elements (Dlx3 II and Dlx3 III) are functional and essential for transcriptional activation of $D k k 1$ promoter. These studies clearly demonstrated the regulation mechanism of DKK1 expression by DLX3.

Previous studies showed many factors, such as growth and differentiation factor-5 (GDF5), insulin-like growth factor, Wnt10A, and Wnt3A, can enhance the proliferation of hDPCs
(Nemoto et al., 2009; Chang et al., 2013; Zhang et al., 2014; Lv et al., 2016). Although the increased proliferation capacity of hDPCs has important implications during regeneration, the hDPCs are usually in a quiescent state in dental pulp under normal conditions (Yan et al., 2011). Thus we investigated the mechanism of how hDPCs maintaining its quiescent state. Wnt signaling can be subdivided into canonical and non-canonical pathways. Non-canonical Wnt signaling antagonizes canonical Wnt signaling (Mikels and Nusse, 2006). Non-canonical Wnt signaling maintains quiescent state of hematopoietic stem cells (HSC) (Sugimura et al., 2012). Along with the activation of HSCs, non-canonical Wnt signaling was attenuated and canonical Wnt signaling was enhanced (Sugimura et al., 2012). During hair follicle growth, canonical Wnt signaling is generally believed to be inactive in the quiescent telogen bulge (Hsu and Fuchs, 2012), and when bulge cells are activated to undergo the transition from telogen to anagen, canonical Wnt signaling becomes strongly elevated (Lien et al., 2014). In $\beta$-catenin conditional knockout mice, hair follicle stem cells (HFSCs) remained quiescent and showed no signs of anagen re-entry (Lien et al., 2014). In the cell cycle of myoblasts, canonical Wnt inhibitors Dkk3 and Rgs2 were more strongly induced during G0 entry, and rapid suppression upon cell cycle re-entry (Subramaniam et al., 2014), which indicates cells in a canonical Wnt-rich environment does not hold for quiescence. Based on these researches, we inferred the inhibited canonical Wnt signaling might play important role in quiescence of hDPCs. In our present study, we found DLX3 inhibited the proliferation of hDPCs and maintained quiescence of the cells indeed through inactivation of canonical Wnt/ $\beta$-catenin signaling pathway, which is confirmed by the evidence that $\mathrm{LiCl}$ treatment reversed the inhibited proliferation ability of $\mathrm{hDPC} / D l \times 3$ cells.

Above all, in the present investigation we elucidate the mechanism of DLX3 in inhibiting proliferation and maintaining the quiescence of hDPCs, which will help to understand the homeostasis of dental pulp in normal physiological conditions.

\section{AUTHOR CONTRIBUTIONS}

$\mathrm{YZ}$ and XL performed most of the experiments, collected and analyzed the data, and prepared the figures. XG performed some of the experiments. MF provided advice and revised the manuscript. GYu and GYa designed the experiments, interpreted the experimental results, and drafted the manuscript. All authors approved the final version of the manuscript.

\section{FUNDING}

This study was supported by the grants from the National Natural Science Foundation of China (81570942, 81470708, and 81670952) and Shandong Provincial Natural Science Foundation of China (BS2015SW001). 


\section{REFERENCES}

Adaimy, L., Chouery, E., Megarbane, H., Mroueh, S., Delague, V., Nicolas, E., et al. (2007). Mutation in WNT10A is associated with an autosomal recessive ectodermal dysplasia: the odonto-onycho-dermal dysplasia. Am. J. Hum. Genet. 81, 821-828. doi: 10.1086/520064

Ahn, Y., Sanderson, B. W., Klein, O. D., and Krumlauf, R. (2010). Inhibition of Wnt signaling by Wise (Sostdc1) and negative feedback from Shh controls tooth number and patterning. Development 137, 3221-3231. doi: 10.1242/dev. 054668

Arya, M., Thrasivoulou, C., Henrique, R., Millar, M., Hamblin, R., Davda, R., et al. (2015). Targets of Wnt/ss-catenin transcription in penile carcinoma. PLoS One 10:e0124395. doi: 10.1371/journal.pone.0124395

Aurrekoetxea, M., Irastorza, I., García-Gallastegui, P., Jiménez-Rojo, L., Nakamura, T., Yamada, Y., et al. (2016). Wnt/ $\beta$-catenin regulates the activity of epiprofin/Sp6, SHH, FGF, and BMP to coordinate the stages of odontogenesis. Front. Cell Dev. Biol. 4:25. doi: 10.3389/fcell.2016.00025

Bejsovec, A. (2005). Wnt pathway activation: new relations and locations. Cell 120, 11-14. doi: 10.1016/j.cell.2004.12.021

Chang, M. C., Lin, L. D., Tseng, H. C., Chang, B. E., Chan, C. P., Lee, S. Y., et al. (2013). Growth and differentiation factor-5 regulates the growth and differentiation of human dental pulp cells. J. Endod. 39, 1272-1277. doi: 10. 1016/j.joen.2013.06.003

Chen, J., Lan, Y., Baek, J. A., Gao, Y., and Jiang, R. (2009). Wnt/beta-catenin signaling plays an essential role in activation of odontogenic mesenchyme during early tooth development. Dev. Biol. 334, 174-185. doi: 10.1016/j.ydbio. 2009.07.015

Cruciat, C. M., and Niehrs, C. (2013). Secreted and transmembrane wnt inhibitors and activators. Cold Spring Harb. Perspect. Biol. 5:a015081. doi: 10.1101/ cshperspect.a015081

Du, Y., Ling, J., Wei, X., Ning, Y., Xie, N., Gu, H., et al. (2012). Wnt/betacatenin signaling participates in cementoblast/osteoblast differentiation of dental follicle cells. Connect. Tissue Res. 53, 390-397. doi: 10.3109/03008207. 2012.668980

Duverger, O., Zah, A., Isaac, J., Sun, H. W., Bartels, A. K., Lian, J. B., et al. (2012). Neural crest deletion of Dlx3 leads to major dentin defects through downregulation of Dspp. J. Biol. Chem. 287, 12230-12240. doi: 10.1074/jbc.M111. 326900

Feledy, J. A., Morasso, M. I., Jang, S. I., and Sargent, T. D. (1999). Transcriptional activation by the homeodomain protein distal-less 3. Nucleic Acids Res. 27, 764-770. doi: 10.1093/nar/27.3.764

Fjeld, K., Kettunen, P., Furmanek, T., Kvinnsland, I. H., and Luukko, K. (2005). Dynamic expression of Wnt signaling-related Dickkopf1, -2, and -3 mRNAs in the developing mouse tooth. Dev. Dyn. 233, 161-166. doi: 10.1002/dvdy. 20285

Gong, Q., Wang, R., Jiang, H., Lin, Z., and Ling, J. (2012). Alteration of microRNA expression of human dental pulp cells during odontogenic differentiation. J. Endod. 38, 1348-1354. doi: 10.1016/j.joen.2012.06.016

Han, X. L., Liu, M., Voisey, A., Ren, Y. S., Kurimoto, P., Gao, T., et al. (2011). Post natal effect of overexpressed DKK1 on mandibular molar formation. J. Dent. Res. 90, 1312-1317. doi: 10.1177/0022034511421926

Harichane, Y., Hirata, A., Dimitrova-Nakov, S., Granja, I., Goldberg, A., Kellermann, O., et al. (2011). Pulpal progenitors and dentin repair. Adv. Dent. Res. 23, 307-312. doi: 10.1177/0022034511405322

Hedgepeth, C. M., Conrad, L. J., Zhang, J., Huang, H. C., Lee, V. M., and Klein, P. S. (1997). Activation of the Wnt signaling pathway: a molecular mechanism for lithium action. Dev. Biol. 185, 82-91. doi: 10.1006/dbio.1997.8552

Hsu, Y. C., and Fuchs, E. (2012). A family business: stem cell progeny join the niche to regulate homeostasis. Nat. Rev. Mol. Cell Biol. 13, 103-114. doi: 10. 1038/nrm3272

Hwang, J., Mehrani, T., Millar, S. E., and Morasso, M. I. (2008). Dlx3 is a crucial regulator of hair follicle differentiation and cycling. Development 135 , 3149-3159. doi: 10.1242/dev.022202

Isaac, J., Erthal, J., Gordon, J., Duverger, O., Sun, H. W., Lichtler, A. C., et al. (2014). DLX3 regulates bone mass by targeting genes supporting osteoblast differentiation and mineral homeostasis in vivo. Cell Death Differ. 21, 1365-1376. doi: 10.1038/cdd.2014.82
Kaur, K., Vig, S., Srivastava, R., Mishra, A., Singh, V. P., Srivastava, A. K., et al. (2015). Elevated hepatic miR-22-3p expression impairs gluconeogenesis by silencing the Wnt-responsive transcription factor Tcf7. Diabetes Metab. Res. Rev. 64, 3659-3669. doi: 10.2337/db14-1924

Kawano, Y., and Kypta, R. (2003). Secreted antagonists of the Wnt signalling pathway. J. Cell Sci. 116, 2627-2634. doi: 10.1242/jcs.00623

Kim, H. K., Oxendine, I., and Kamiya, N. (2013). High-concentration of BMP2 reduces cell proliferation and increases apoptosis via DKK1 and SOST in human primary periosteal cells. Bone 54, 141-150. doi: 10.1016/j.bone.2013. 01.031

Kim, J. H., Liu, X., Wang, J., Chen, X., Zhang, H., Kim, S. H., et al. (2013). Wnt signaling in bone formation and its therapeutic potential for bone diseases. Ther. Adv. Musculoskelet Dis. 5, 13-31. doi: 10.1177/1759720X1 2466608

Kim, T. H., Bae, C. H., Lee, J. C., Ko, S. O., Yang, X., Jiang, R., et al. (2013). Beta catenin is required in odontoblasts for tooth root formation. J. Dent. Res. 92, 215-221. doi: 10.1177/0022034512470137

Li, X., Yang, G., and Fan, M. (2012). Effects of homeobox gene distal-less 3 on proliferation and odontoblastic differentiation of human dental pulp cells. J. Endod. 38, 1504-1510. doi: 10.1016/j.joen.2012.07.009

Liang, S., Zhang, S., Wang, P., Yang, C., Shang, C., Yang, J., et al. (2017). LncRNA, TUG1 regulates the oral squamous cell carcinoma progression possibly via interacting with Wnt/beta-catenin signaling. Gene 608, 49-57. doi: 10.1016/j. gene.2017.01.024

Lien, W. H., Polak, L., Lin, M., Lay, K., Zheng, D., and Fuchs, E. (2014). In vivo transcriptional governance of hair follicle stem cells by canonical Wnt regulators. Nat. Cell Biol. 16, 179-190. doi: 10.1038/ncb2903

Liu, F., Chu, E. Y., Watt, B., Zhang, Y., Gallant, N. M., Andl, T., et al. (2008). $\mathrm{Wnt} /$ beta catenin signaling directs multiple stages of tooth morphogenesis. Dev. Biol. 313, 210-224. doi: 10.1016/j.ydbio.2007.10.016

Liu, Y., Liu, Y. Z., Zhang, R. X., Wang, X., Meng, Z. J., Huang, J., et al. (2014). Oridonin inhibits the proliferation of human osteosarcoma cells by suppressing Wnt/beta-catenin signaling. Int. J. Oncol. 45, 795-803. doi: 10.3892/ijo.2014. 2456

Logan, C. Y., and Nusse, R. (2004). The Wnt signaling pathway in development and disease. Annu. Rev. Cell Dev. Biol. 20, 781-810. doi: 10.1146/annurev.cellbio.20. 010403.113126

Lv, T., Wu, Y., Mu, C., Liu, G., Yan, M., Xu, X., et al. (2016). Insulin-like growth factor 1 promotes the proliferation and committed differentiation of human dental pulp stem cells through MAPK pathways. Arch. Oral. Biol. 72, 116-123. doi: 10.1016/j.archoralbio.2016.08.011

MacDonald, B. T., Tamai, K., and He, X. (2009). Wnt/beta-catenin signaling: components, mechanisms, and diseases. Dev. Cell 17, 9-26. doi: 10.1016/j. devcel.2009.06.016

Mikels, A. J., and Nusse, R. (2006). Purified Wnt5a protein activates or inhibits beta catenin-TCF signaling depending on receptor context. PLoS Biol. 4:e115. doi: 10.1371/journal.pbio.0040115

Morasso, M. I., Grinberg, A., Robinson, G., Sargent, T. D., and Mahon, K. A. (1999). Placental failure in mice lacking the homeobox gene Dlx3. Proc. Natl. Acad. Sci. U.S.A. 96, 162-167. doi: 10.1073/pnas.96.1.162

Morasso, M. I., Mahon, K. A., and Sargent, T. D. (1995). A Xenopus distal-less gene in transgenic mice: conserved regulation in distal limb epidermis and other sites of epithelial-mesenchymal interaction. Proc. Natl. Acad. Sci. U.S.A. 92, 3968-3972. doi: 10.1073/pnas.92.9.3968

Nemoto, E., Koshikawa, Y., Kanaya, S., Tsuchiya, M., Tamura, M., Somerman, M. J., et al. (2009). Wnt signaling inhibits cementoblast differentiation and promotes proliferation. Bone 44, 805-812. doi: 10.1016/j.bone.2008.12.029

Potdar, P. D., and Jethmalani, Y. D. (2015). Human dental pulp stem cells: applications in future regenerative medicine. World J. Stem Cells 7, 839-851. doi: 10.4252/wjsc.v7.i5.839

Rao, T. P., and Kuhl, M. (2010). An updated overview on Wnt signaling pathways: a prelude for more. Circ. Res. 106, 1798-1806. doi: 10.1161/CIRCRESAHA.110. 219840

Rattanawarawipa, P., Pavasant, P., Osathanon, T., and Sukarawan, W. (2016) Effect of lithium chloride on cell proliferation and osteogenic differentiation in stem cells from human exfoliated deciduous teeth. Tissue Cell 48, 425-431. doi: 10.1016/j.tice.2016.08.005 
Robinson, G. W., and Mahon, K. A. (1994). Differential and overlapping expression domains of Dlx-2 and Dlx-3 suggest distinct roles for distal-less homeobox genes in craniofacial development. Mech. Dev. 48, 199-215. doi: 10.1016/ 09254773(94)900604

Sasaki, T., Ito, Y., Xu, X., Han, J., Bringas, P., Maeda, T., et al. (2005). LEF1 is a critical epithelial survival factor during tooth morphogenesis. Dev. Biol. 278, 130-143. doi: 10.1016/j.ydbio.2004.10.021

Sinanan, A. C., Hunt, N. P., and Lewis, M. P. (2004). Human adult craniofacial muscle derived cells: neural-cell adhesion-molecule (NCAM; CD56)-expressing cells appear to contain multipotential stem cells. Biotechnol. Appl. Biochem. 40, 25-34. doi: 10.1042/BA20030185

Subramaniam, S., Sreenivas, P., Cheedipudi, S., Reddy, V. R., Shashidhara, L. S., Chilukoti, R. K., et al. (2014). Distinct transcriptional networks in quiescent myoblasts: a role for Wnt signaling in reversible vs. irreversible arrest. PLoS One 8:e65097. doi: 10.1371/journal.pone.0065097

Sugimura, R., He, X. C., Venkatraman, A., Arai, F., Box, A., Semerad, C., et al. (2012). Noncanonical Wnt signaling maintains hematopoietic stem cells in the niche. Cell 150, 351-365. doi: 10.1016/j.cell.2012.05.041

Tatullo, M., Marrelli, M., Shakesheff, K. M., and White, L. J. (2015). Dental pulp stem cells: function, isolation and applications in regenerative medicine. J. Tissue Eng. Regen. Med. 9, 1205-1216. doi: 10.1002/term. 1899

Viale-Bouroncle, S., Klingelhoffer, C., Ettl, T., Reichert, T. E., and Morsczeck, C. (2015). A protein kinase A (PKA)/beta-catenin pathway sustains the BMP2/DLX3 induced osteogenic differentiation in dental follicle cells (DFCs). Cell. Signal. 27, 598-605. doi: 10.1016/j.cellsig.2014. 12.008
Yan, M., Yu, Y., Zhang, G., Tang, C., and Yu, J. (2011). A journey from dental pulp stem cells to a bio-tooth. Stem Cell Rev. 7, 161-171. doi: 10.1007/s12015-0109155-0

Yang, G., Yuan, G., MacDougall, M., Chen, Z., and Chen, S. (2017). BMP-2 induced Dspp transcription is mediated by $\mathrm{Dlx} 3 /$ Osx signaling pathway in odontoblasts. Sci. Rep. 7:10775. doi: 10.1038/s41598-017-10908-8

Zhang, Z., Guo, Q., Tian, H., Lv, P., Zhou, C., and Gao, X. (2014). Effects of WNT10A on proliferation and differentiation of human dental pulp cells. J. Endod. 40, 1593-1599. doi: 10.1016/j.joen.2014.07.009

Zhao, Z., Stock, D., Buchanan, A., and Weiss, K. (2000). Expression of Dlx genes during the development of the murine dentition. Dev. Genes Evol. 210, 270-275. doi: $10.1007 / \mathrm{s} 004270050314$

Zhou, J., Jiang, J., Wang, S., and Xia, X. (2016). DKK1 inhibits proliferation and migration in human retinal pigment epithelial cells via the Wnt/beta-catenin signaling pathway. Exp. Ther. Med. 12, 859-863. doi: 10.3892/etm.2016.3422

Conflict of Interest Statement: The authors declare that the research was conducted in the absence of any commercial or financial relationships that could be construed as a potential conflict of interest.

Copyright (c) 2018 Zhan, Li, Gou, Yuan, Fan and Yang. This is an open-access article distributed under the terms of the Creative Commons Attribution License (CC BY). The use, distribution or reproduction in other forums is permitted, provided the original author(s) and the copyright owner(s) are credited and that the original publication in this journal is cited, in accordance with accepted academic practice. No use, distribution or reproduction is permitted which does not comply with these terms. 